\title{
CORROSIVE PROPERTIES DISTRIBUTION IN AW-7020 ALLOY JOINTS WELDED BY FSW
}

\author{
Krzysztof Dudzik \\ Gdynia Maritime University, Faculty of Marine Engineering \\ Morska Street 81-87, 81-225 Gdynia, Poland \\ tel.: +485869015 49, fax: +48586901399 \\ e-mail:kdudzik@am.gdynia.pl
}

\begin{abstract}
The results of corrosion properties research of aluminum alloy AW 7020 (AlZn5Mg1) welded by Friction Stir Welding were presented. In the article the parameters for friction stir welding of sheets made of AlZn5Mg1 (7020) alloy were presented. Corrosion tests were performed on the surface of the FSW joined sheets depending on the distance from the centre of the weld.

EIS measurement was performed in three-electrode system in an artificial seawater (3.5\% $\mathrm{NaCl})$. Impedance studies were carried out at the corrosion potential. Changed voltage signal amplitude in the range $\pm 10 \mathrm{mV}$ and frequency range of changes was as follows: $100 \mathrm{kHz}-0.1 \mathrm{~Hz}$. Atlas $0531 \mathrm{EU} \& \mathrm{IA}$ potentiostat was used for studies. Model in the form of an electrical equivalent circuit replacement was chosen for the test object. The results of electrochemical impedance spectroscopy are presented graphically in the Nyquist charts matched with the theoretical curve to them and in the form of parameters characterizing the corrosion process. Obtained results were statistically analysed.

Better resistance to electrochemical corrosion was found for the native material then joint welded by FSW of 7020 aluminum alloy. Worse corrosion properties were observed in the advancing side of the weld than in the retreating side of the weld. alloy.

Original value are received results of the corrosion properties distribution of FSW welded AW-7020 aluminium
\end{abstract}

Keywords: Electrochemical Impedance Spectroscopy (EIS), Friction Stir Welding (FSW), welding, corrosion

\section{Introduction}

Aluminium alloys are getting more and more interest in the shipbuilding industry as these alloys allow a significant reduction in ship structure weight compared with the weight of steel structures. The use of aluminium reduces the weight by about $50 \%$, thereby increasing the displacement of the vessel and maintaining the displacement for load or speed increase and stability improvement. Among weldable Al-alloys suitable to plastic working the group of Al-Mg alloys (of 5xxx-series) of good weldability and relatively good service conditions are still the most popular. The advantage of these alloys is their relative insensitivity to layer corrosion and stress corrosion, the disadvantage - low strength of welded joints, below $300 \mathrm{MPa}$. An alternative to these alloys could be the Al-Zn-Mg (7xxx series) alloys. They exhibit higher strength properties than the mechanical properties of Al-Mg alloys. The disadvantage of the 7xxx series alloys is that they are prone to stress and layer corrosion. Many years of research have shown that the resistance of these alloys to stress corrosion is influenced among other things by heat processing, chemical composition and welding technology (welding method, type of fillers, type of joint) [1-7]. Virtually all joints welded using conventional MIG or TIG methods in this group of alloys possess insufficient resistance to stress or layer corrosion. An alternative to the traditional method of MIG welding is a friction stir welding FSW. It is based on a combination of structural elements in the solid state (below the melting point) so that the properties of joints may be higher than traditional welds MIG, TIG [1-3, 5-7, 9].

Currently, one of the best research methods of resistance to this type of corrosion is electrochemical impedance spectroscopy (EIS). It allows not only determine the electrochemical 
corrosion resistance but also gives the opportunity to evaluate homogeneity of the corrosion process on the metal surface $[5,8,10-13]$.

The aim of this paper is to determine the susceptibility to the electrochemical corrosion of AW7020 (AlZn5Mg1) alloy joints welded by FSW in artificial seawater environment and what is the corrosive properties distribution in welded construction comparison depends on distance from the weld.

\section{The research methodology}

The testing used EN AW-7020 T6 aluminium alloy (supersaturated and artificially aged) the chemical composition of the alloy is given in tab. 1.

Tab. 1. Chemical composition of 7020 aluminum alloy

\begin{tabular}{|c|c|c|c|c|c|c|c|c|c|}
\hline \multicolumn{10}{|c|}{ Chemical composition (\%) } \\
\hline $\mathrm{Si}$ & $\mathrm{Fe}$ & $\mathrm{Cu}$ & $\mathrm{Mn}$ & $\mathrm{Mg}$ & $\mathrm{Cr}$ & $\mathrm{Zn}$ & $\mathrm{Ti}$ & $\mathrm{Zr}$ & $\mathrm{Al}$ \\
\hline 0.30 & 0.35 & 0.10 & 0.24 & 1.30 & 0.14 & 4.70 & 0.08 & 0.07 & the rest \\
\hline
\end{tabular}

Technology development of Friction Stir Welding (FSW) method for joining AW-7020 aluminium alloy elements was carried out using a conventional vertical milling machine FYF32JU2, adapted for FSW. A view of the rotating mandrel head and table with fixed joined sheets is shown in Fig. 1. The FSW machine is equipped with the necessary instrumentation: handles rigid mounting plates and tool cooling system.

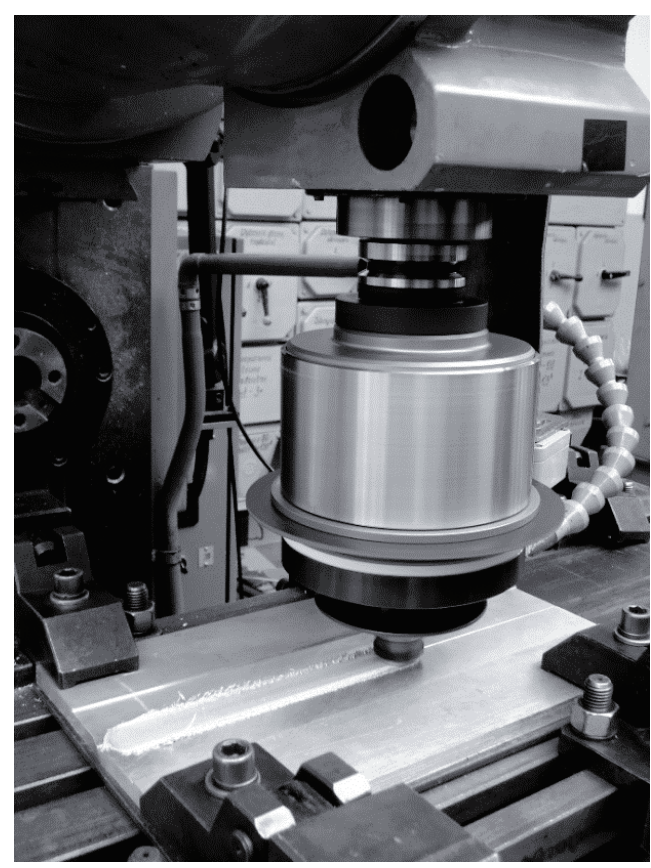

Fig. 1. FSW machine used in research

During research tool with a „TRI-FLUTE” pin, made of high-speed steel HZ-5-2 (SW7M) were used. As shown by preliminary tests, the tool made of such steel is equivalent to the welding tools designed for the friction stir welding of aluminium alloys $5 \mathrm{xxx}$ and $7 \mathrm{xxx}$ series. This means that it is capable of withstanding temperatures in which the plastic deformation process occurs, mixing and forcing the metal around the mandrel, and there is no excess bonding material to the tool shoulder. The shape of ,TRI-FLUTE” tool, which was used in research, is shown in Fig. 2. 


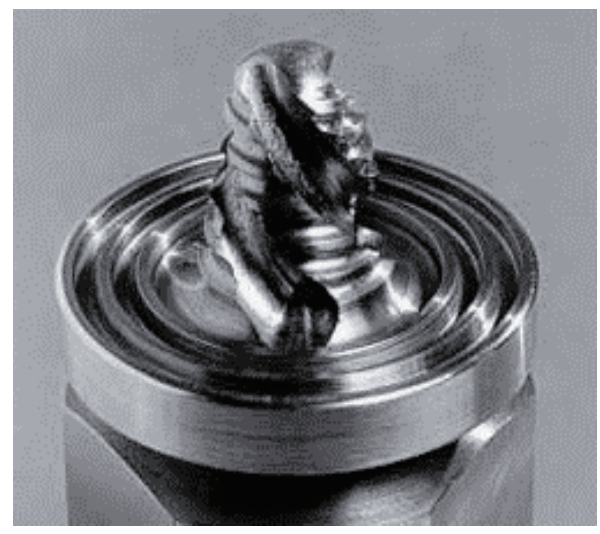

Fig. 2. TRI-FLUTE tool used in research

Joints were both sides welded, using the same parameters on both sides of the joined elements. The thickness of the joining sheets was $\mathrm{g}=12 \mathrm{~mm}$. The sheets were one side milled to a thickness of $10 \mathrm{~mm}$ in the contact portion. Accordingly, rigid mounting plate was ensured by welding machine equipment. Except to providing general cleanliness of the sheets there was not used any degreasing agent interfaces connected elements. Plates were joined on both sides with the same parameters, which are shown in Tab. 2. The diagram of friction stir welding is shown in Fig. 3 and location of characteristic areas in the weld in Fig. 4.

Tab. 2. Chosen FSW parameters of 7020 aluminium alloy sheets

\begin{tabular}{|c|c|c|c|c|c|}
\hline \multicolumn{3}{|c|}{ Tool dimensions } & \multirow{2}{*}{$\begin{array}{c}\text { Angle of tool } \\
\text { deflection } \\
\alpha_{z} \\
{\left[^{\circ}\right]}\end{array}$} & \multirow{2}{*}{$\begin{array}{c}\text { Mandrel's rotary } \\
\text { speed } \\
\mathrm{V}_{\mathrm{n}} \\
{[\mathrm{rpm}]}\end{array}$} & \multirow{2}{*}{$\begin{array}{c}\text { Welding speed } \\
\mathrm{V}_{\mathrm{z}} \\
{[\mathrm{mm} / \mathrm{min}]}\end{array}$} \\
\hline $\begin{array}{c}\mathrm{D} \\
{[\mathrm{mm}]}\end{array}$ & $\underset{[\mathrm{mm}]}{\mathrm{d}}$ & $\begin{array}{c}\mathrm{h} \\
{[\mathrm{mm}]}\end{array}$ & & & \\
\hline 25 & 10 & 5.8 & 88.5 & 450 & 180 \\
\hline
\end{tabular}

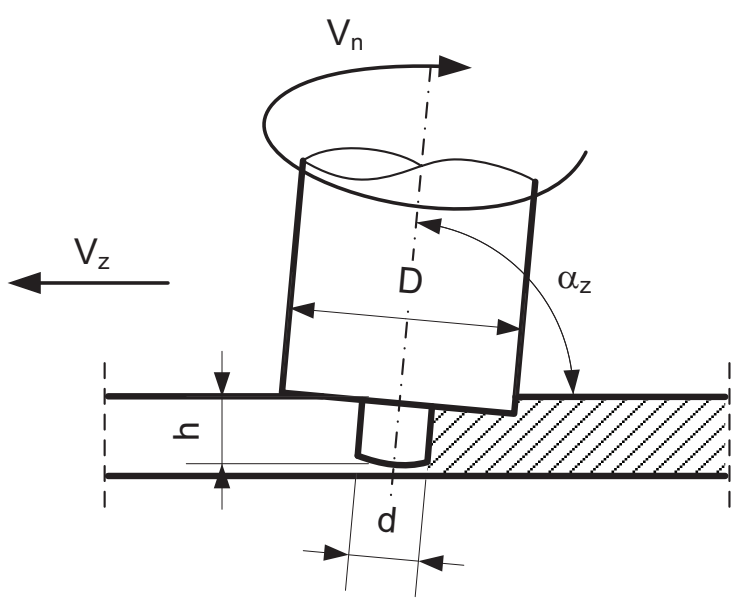

Fig. 3. The diagram of FSW [7]

The corrosion resistance research was carried out using three-electrode method. Used in studies three-electrode system consists of the following elements: the sample, an auxiliary electrode (polarizing) of titanium and platinum reference electrode (saturated calomel electrode) were placed in a tank with $3.5 \%$ water solution $\mathrm{NaCl}$. Active surface samples were $1 \mathrm{~cm}^{2}$. Samples attached to copper wires, PVC insulated. Not tested surface is isolated from the corrosive environment. Before the measurements, the samples were exposed in the electrolyte to stabilize the corrosion potential. During measuring, the electrolyte was continuously mixed using a magnetic stirrer [5, 8, 10-12]. The samples were degreased before the test. 


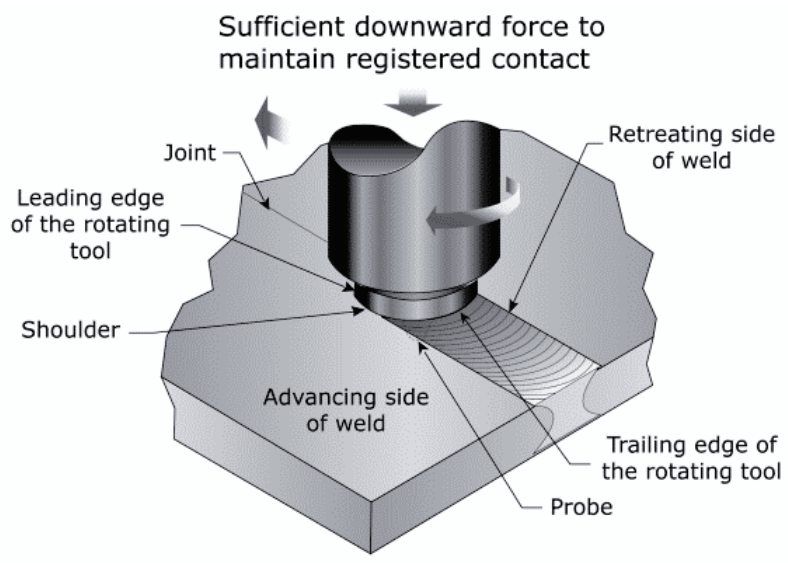

Fig. 4. Typical diagrammatic representation of FSW process showing the terminology associated with the way in which material is displaced from the tool [14]

Atlas 0531EU \& IA potentiostat was used for studies.

Electrochemical impedance spectroscopy measurements were conducted at the corrosion potential. The amplitude of the voltage signal varied in the range $\pm 10 \mathrm{mV}$, and the extent of the changes was the signal frequency: $100 \mathrm{kHz}-0.1 \mathrm{~Hz}$. Studies have been conducted from high to low frequencies [10].

Determination of the corrosion process parameters was performed computer programs: AtlasLab 2.0 and EIS Spectrum Analyser.

Chosen for the test object model in the form of an electrical equivalent circuit of the replacement.

Selected model electrical circuit showing a replacement is presented in Fig. 5.

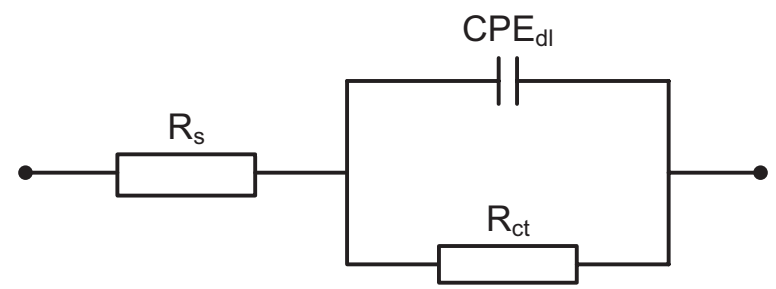

Fig. 5. The selected replacement of corrosion electrical circuit

In the selected model, the $\mathrm{R}_{\mathrm{s}}$ element is the electrolyte resistance, which is reflected in corrosive environment. $R_{c t}$ element is characterized by the charge transfer resistance of the interface metal / electrolyte, associated with the process of oxidation of metal, while the constant phase element $\mathrm{CPE}_{\mathrm{dl}}$ - double layer capacitance, occurring on the border of phases under consideration.

For the selected alternative resultant impedance of the circuit can be described by the following relationship:

where:

$$
Z=R_{s}+\frac{1}{\frac{1}{R_{c t}}+C P E_{d l}(j \omega)^{n_{d l}}},
$$

$\mathrm{R}_{\mathrm{S}} \quad$ - electrolyte resistance,

$\mathrm{R}_{\mathrm{ct}}$ - charge transfer resistance,

$\mathrm{CPE}_{\mathrm{dl}}$ - double layer capacitance,

$\mathrm{n}_{\mathrm{dl}}$ - exponent determining the homogeneity of corrosion process,

๑ - pulsation, frequency derivative,

$\mathrm{j}-$ - unit imaginary number. 


\section{The research results}

The results of the electrochemical impedance spectroscopy of samples of 7020 alloy joint welded by FSW were computer processed. As a result, set the parameters characterizing the corrosion process, where the average values of five samples are presented in Tab. 3. These parameters define the individual components of the model - a replacement circuit chosen in accordance with the methodology of the study.

Tab. 3. Parameters of the replacement corrosive electrical circuit of 7020 joint welded by FSW

\begin{tabular}{|c|c|c|c|c|c|c|c|c|}
\hline Specimen & $\begin{array}{c}\mathrm{R}_{\mathrm{s}} \\
{\left[\Omega \cdot \mathrm{cm}^{2}\right]}\end{array}$ & $\begin{array}{c}\text { Std. } \\
\text { Dev. }\end{array}$ & $\begin{array}{c}\mathrm{R}_{\mathrm{ct}} \\
{\left[\Omega \cdot \mathrm{cm}^{2}\right]}\end{array}$ & $\begin{array}{c}\text { Std. } \\
\text { Dev. }\end{array}$ & $\begin{array}{c}\mathrm{CPE}_{\mathrm{dl}} \\
{\left[\mu \mathrm{F} / \mathrm{cm}^{2}\right]}\end{array}$ & $\begin{array}{c}\text { Std. } \\
\text { Dev. }\end{array}$ & $\begin{array}{c}\mathrm{n}_{\mathrm{dl}} \\
{[-]}\end{array}$ & $\begin{array}{c}\text { Std. } \\
\text { Dev. }\end{array}$ \\
\hline $\begin{array}{c}\text { Native } \\
\text { material }\end{array}$ & 0.98 & 0.21 & 876.83 & 126.13 & 44.23 & 14.08 & 0.94 & 0.01 \\
\hline $\begin{array}{c}\text { Advancing } \\
\text { Side HAZ }\end{array}$ & 0.87 & 0.12 & 802.08 & 96.64 & 51.26 & 9.17 & 0.94 & 0.02 \\
\hline $\begin{array}{c}\text { Advancing } \\
\text { Side }\end{array}$ & 1.03 & 0.08 & 601.47 & 64.83 & 70.38 & 13.11 & 0.92 & 0.03 \\
\hline Weld & 1.14 & 0.15 & 558.11 & 85.74 & 79.87 & 18.72 & 0.96 & 0.02 \\
\hline $\begin{array}{c}\text { Retreating } \\
\text { Side }\end{array}$ & 0.91 & 0.34 & 868.69 & 77.38 & 46.65 & 6.88 & 0.91 & 0.01 \\
\hline $\begin{array}{c}\text { Retreating } \\
\text { Side HAZ }\end{array}$ & 0.99 & 0.27 & 822.12 & 52.40 & 63.92 & 11.43 & 0.95 & 0.02 \\
\hline
\end{tabular}

Where Std. Dev. - the standard deviation, HAZ - heat affected zone.

The best corrosion properties were obtained for the native material and the worst for the joint welded by FSW. The most important parameter determining the susceptibility to electrochemical corrosion $\mathrm{R}_{\mathrm{ct}}$ - charge transfer resistance, reaches the highest value for the sample of native material and the lowest value for the sample from the centre of the weld. Corrosion properties of other tested samples reach values slightly smaller than native material; however, the differences are within the standard deviation. The exception is the sample from the advancing side of weld. In this case, the parameters achieved during the research are almost the same as for the sample from the weld.

The exemplary results of the electrochemical impedance spectroscopy are shown graphically in Nyquist and Bode charts (Fig. 6 and 7), and matched them with the theoretical curve.

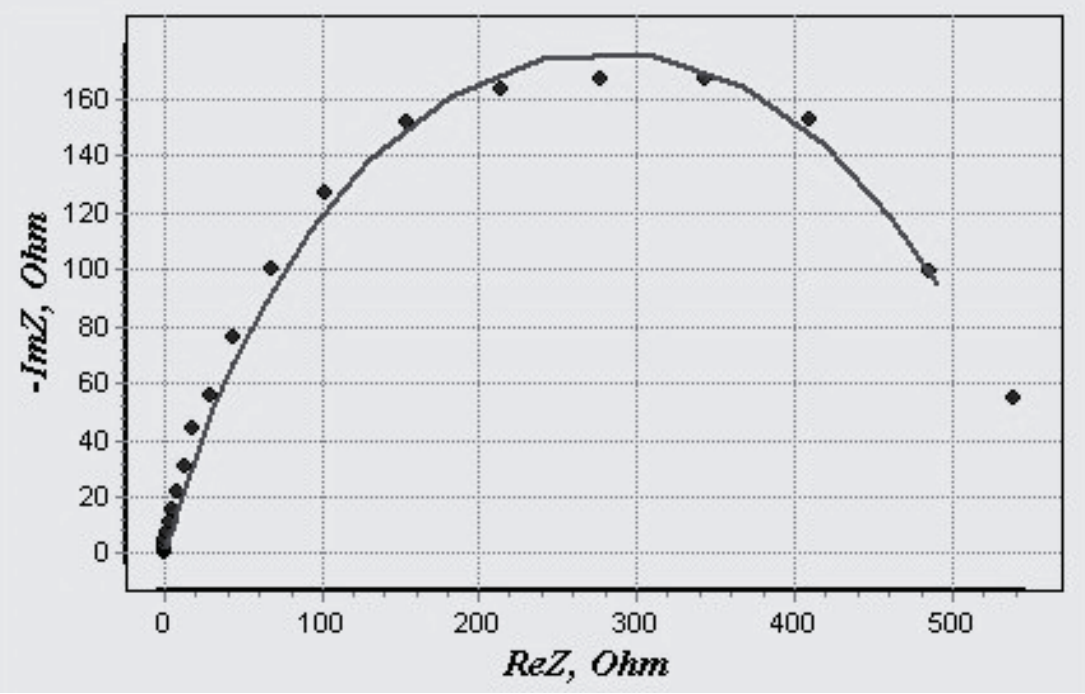

Fig. 6. An example of the Nyquist chart for a sample of the weld jointed by FSW 


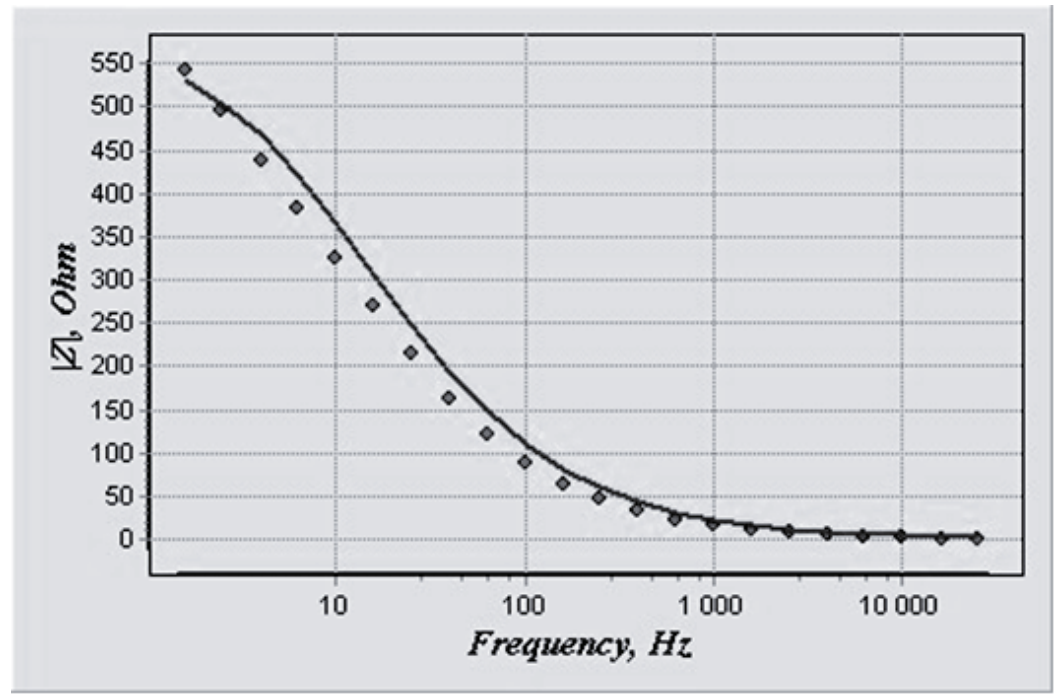

Fig. 7. An example of the Bode chart for a sample of the weld jointed by FSW

The analysis showed the compatibility frequency impedance characteristics determined experimentally with the characteristics of computer-calculated for the selected model - the replacement of an electrical circuit, in the whole range of frequency changes extortion. This confirms the correctness of chosen model for testing and guarantees the reliability of the results.

\section{Summary}

Analysis of the electrochemical impedance spectroscopy showed that the native material has more resistance to electrochemical corrosion than FSW welded joint. Charge transfer resistance value by a double layer of $\mathrm{R}_{\mathrm{ct}}$ is smaller for a sample jointed by FSW, which indicates a lower resistance to withstand the charge exchange (ions, electrons) between the material and the electrolyte. $\mathrm{R}_{\mathrm{ct}}$ parameter value during the test for sample of the native material, reached about $57 \%$ higher than the joint welded by FSW.

The second parameter describing the corrosion process is the double layer capacitance $\mathrm{CPE}_{\mathrm{dl}}$. For researched specimens $\mathrm{CPE}_{\mathrm{dl}}$ takes the highest value (the worst situation) in case of the weld and the lowest value for native material. This parameter is not as important in the evaluation of corrosion resistance as electrochemical charge-transfer resistance $\mathrm{R}_{\mathrm{ct}}[5,12,13]$.

The component power exponent of capacitive impedance $n_{d l}$ (of equivalent circuit), determining the homogeneity of corrosion is the lowest for Retreating Side of weld. This indicates a greater tendency to pitting corrosion was for FSW joints. Despite the differences in values that occur, $\mathrm{n}_{\mathrm{dl}}$ parameter for each sample, the values are relatively high which indicates a high homogeneity of the processes of corrosion in whole joint.

Electrolyte resistance $R_{\text {est }}$ which is corrosive environment for all the samples was the same level and to receive very low values (several hundred times smaller than the charge transfer resistance), which indicates a very high electrical conductivity of the solution. This parameter is not critical in the consideration of corrosion resistance of the samples.

In summary, studies on the electrochemical corrosion resistance made by the EIS method showed that the FSW welded joint and advancing side of weld are less resistant than native material AW-7020, for this type of degradation in seawater environment.

\section{References}

[1] Czechowski, M., Effect of anodic polarization on stress corrosion cracking of some aluminium alloys, Advances in Materials Science, Vol. 7, No. 1(11), pp. 13-20, 2007. 
[2] Czechowski, M., Low-cycle fatigue of friction stir welded Al-Mg alloys. Journal of Materials Processing Technology, 164-165, 1001-1006, 2005.

[3] Czechowski, M., Własności złączy doczołowych blach ze stopów Al-Mg spajanych różnymi metodami, Materiały i Technologie, Politechnika Gdanska, Nr 1(1), Gdansk 2003.

[4] Czechowski, M., Zieliński, A., Effect of cathodic polarization on failure and degradation of mechanical properties of some aluminium alloys, Scripta Metallurgy Materials, Vol. 30, 1994.

[5] Dudzik, K., Charchalis, A., EIS research of $A W-7020$ alloy joint welded by MIG, Journal of KONES Powertrain and Transport, Vol. 19, No. 1, Warsaw 2012.

[6] Dudzik, K., Czechowski, M., Analysis of possible shipbuilding application of Friction Stir Welding (FSW) method to joining elements made of AlZn5Mgl alloy, Polish Maritime Research, No. 4, 2009.

[7] Dudzik, K., The influence of joining method of AW-7020 aluminium alloy on corrosion properties, Journal of KONES Powertrain and Transport, Vol. 18, No. 4, Warsaw 2011.

[8] Dill, T., Starosta, R., Effect of the ceramic dispersion in the nickel matrix composite coatings on corrosion properties after plastic working, Solid State Phenomena, Vol. 183, 2012.

[9] Ferraris, S, Volpone, L. M., Aluminium alloys in third millennium shipbuilding: materials, technologies, perspectives, The Fifth International Forum on Aluminium Ships, Tokyo, Japan 2005.

[10] Starosta, R., Corrosion of $\mathrm{Ni}-\mathrm{Al}$ and $\mathrm{Ni}-\mathrm{Al}-\mathrm{Al}_{2} \mathrm{O}_{3}$ flame sprayed coatings of Custody 8000 system in $0.01 \mathrm{M} \mathrm{H}_{2} \mathrm{SO}_{4}$ and 3.5\% NaCl solution, Solid State Phenomena, Vol. 183, 2012.

[11] Starosta, R., The influence of plastic strain on the corrosive properties of plasma sprayed intermetallic NiAl and $\mathrm{NI}_{3} \mathrm{Al}$ coatings, Solid State Phenomena, Vol. 165, pp. 165-177, 2010.

[12] Starosta, R., Zieliński, A., Effect of chemical composition on corrosion and wear behaviour of the composite $\mathrm{Ni}-\mathrm{Fe}-\mathrm{Al}_{2} \mathrm{O}_{3}$ coating, Journal of Materials Processing Technology, No 157 158, 2004.

[13] Xiao, Y. P., Pan, Q. L., Li, W. B., Liu, X. Y., He, Y. B., Influence of retrogression and reaging treatment on corrosion behaviour of Al- $\mathrm{Zn}-\mathrm{Mg}-\mathrm{Cu}$ alloy, Materials and Design 32, China 2011.

[14] http://www.hilda-europe.eu. 